\title{
Effect of Ivermectin against Psoroptic mange in rabbits
}

\author{
S. Sivajothi ${ }^{1 *}$, B.Sudhakara Reddy ${ }^{2}$, V.C.Rayulu ${ }^{1}$ \\ ${ }^{1}$ Department of Veterinary Parasitology, \\ ${ }^{2}$ Assistant Professor (Veterinary Medicine), T.V.C.C., \\ College of Veterinary Science, Sri Venkateswara Veterinary University, \\ Proddatur - 516360, Y.S.R.District, Andhra Pradesh, India. \\ *Corresponding author E-mail: sivajothi579@gmail.com
}

Copyright $\odot 2014$ S. Sivajothi et al. This is an open access article distributed under the Creative Commons Attribution License, which permits unrestricted use, distribution, and reproduction in any medium, provided the original work is properly cited.

\begin{abstract}
The present report is on Psoroptic mange infestation in rabbits. Out of 126 rabbits in a farm 34 were infested. Observed clinical signs were alopecia, crusts formation, superficial and deep skin fissures and itching. Distribution of lesions was noticed around the base of ears, margins of the ears and face. Skin scrapings from infested rabbits were examined and

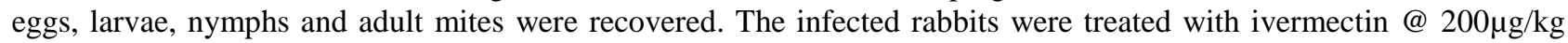
body weight first day subcutaneously followed by orally once in 48 hours along with antibiotic and supportive therapy. Improvement in the condition was noticed after $4^{\text {th }}$ day of therapy.
\end{abstract}

Keywords: Psoriatic mange, Rabbits, Ivermectin.

\section{Introduction}

Psoroptic mange occurs in the ears of domestic and wild animals, particularly in the ears of rabbits. It is caused by Psoroptes cuniculi. It is a common parasitic disease problem in both pet and commercial rabbits. These ear mites do not burrow, they feed on skin tissue, which irritates the skin and causes lesions. The developed lesions produces the scabs, the scabs protect the mites from the environment and shield them from removal by the animal when it scratches. In India with hot and humid climate, the incidence of the skin infections especially mange in the rabbits is very high [1]. Mange leads to listlessness, anorexia, emaciation and even death [2]. This mange may lead to further complication of middle or inner ear, wry neck and deaths resulting in considerable economic losses. Ivermectin, one of the avermectin family compounds, is used as a broad spectrum parasiticide in domestic animals and is also recommended for treatment of ear mange in rabbits. Previously different studies were done on the dose levels and duration in rabbits affected with ear mange [3, $4 \& 5]$. But all the studies were done with parentral administration of ivermectin. But, the present study was carried out to know about the effect of parentral followed by oral administration of ivermectin against Psoroptic mange in rabbits.

\section{Materials and methods}

The present study was carried out on New Zealand White rabbits of both sex and aged between 4 months to 2 years in a farm of 126 rabbits at Yerraguntla, Y.S.R.District. Out of 126 rabbits, 34 had the problem of ear canker. Affected rabbits had the history of scratching of ears, shaking of their head and tensing of neck muscles. Up on clinical examination rabbits revealed the loose crusts at the margins of ears, brown wax and scabs with unpleasant odour inside the ears. Hyperkeratosis along with the scales formation was also noticed (Fig.1). Superficial and deep skin scrapings were taken from the margins of ears, using a blunt scalpel blade dipped in liquid paraffin. The collected sample includes dermis, epidermis, scales and hair. All samples were examined by direct microscopic method to know the vitality of the organisms and each sample was also dissolved in $5 \mathrm{ml}$ of a $10 \%$ solution of sodium hydroxide. The mixture was boiled, centrifuged and the sediment was examined using a light microscope under 10X and 40X magnification to identify the 
causative organism. Examination of the materials revealed presence of the different stages of Psoroptes spp. mange mites.

Infected rabbits were isolated from the other healthy rabbits to prevent the spread of infection. Infected rabbits were treated with oxytetracyclin BID, PO @ $20 \mathrm{mg} / \mathrm{kg}$ body weight for five days, first day subcutaneous ivermectin @ 200 $\mu \mathrm{g} / \mathrm{kg}$ body weight was given, followed by oral administration of ivermectin@ $200 \mu \mathrm{g} / \mathrm{kg}$ body weight once in 48 hours. Rabbits were daily supplemented with liv-52, PO @ $2 \mathrm{ml}$ per day. Weekly once disinfection of the nest areas and surroundings of the sheds with cypermethrin@2ml per 1 liter of water was advised. Clinical and parasitological examination were carried out on $7^{\text {th }}, 14^{\text {th }}$ and $21^{\text {st }}$ day of post treatment to observe the intensity of itching, crusts formation. Microscopic examination of live and dead mites and number of mites per field was also carried out to know about the clinical as well as laboratory cure.

\section{Results and discussion}

34 rabbits (26.9\%) out of 126 rabbits were found to be infested with Psoroptes mange mites. Hyperkeratosis of ear margins, nasal bridge, brown wax in the ears and intense pruritus were the common signs observed in all infected rabbits. Microscopic evaluation of the scrapings revealed the presence of eggs and adult stages of mites. The pedicels of the mites were long and segmented. The tarsal suckers were observed on the pedicels of the first, second, and third pairs of legs in the male mite and on the first, second, and fourth pairs of legs in the adult female mite (Fig.2). Based on the morphology these mites were identified as Psoroptes spp. [6]. In the present study no other ectoparasites were observed. Successful recovery was recorded with ivermectin administration @ $200 \mu \mathrm{g} / \mathrm{kg}$ body weight along with supportive therapy.

Post treatment clinical examination of rabbits on $7^{\text {th }}$ day revealed that there was slight improvement in the skin lesions by disappearance of scales and scrapings from the same area revealed the presence of live and dead mites. But numbers of mites were decreased per field of examination. On $14^{\text {th }}$ day of examination, rabbits were free from itching and alopecia along with the presence of dead mites in scrapings and complete disappearance of scales was observed. On $21^{\text {st }}$ day of therapy, all rabbits were free from eggs and adult stages of mites. After disappearance of crusts, hair growth in previously infested areas was observed in all infested rabbits. Complete cure was noticed clinically and microscopically after completion of the single dose of subcutaneous ivermectin followed by ten doses of oral ivermectin. No adverse clinical reactions were recorded following the administration of ivermectin orally during the study period which is in consonance with the findings of Reddy and Kumari [7]. In recent reports Sarcoptic mange in rabbits was also successfully treated with oral ivermectin without any clinical side effects [8].

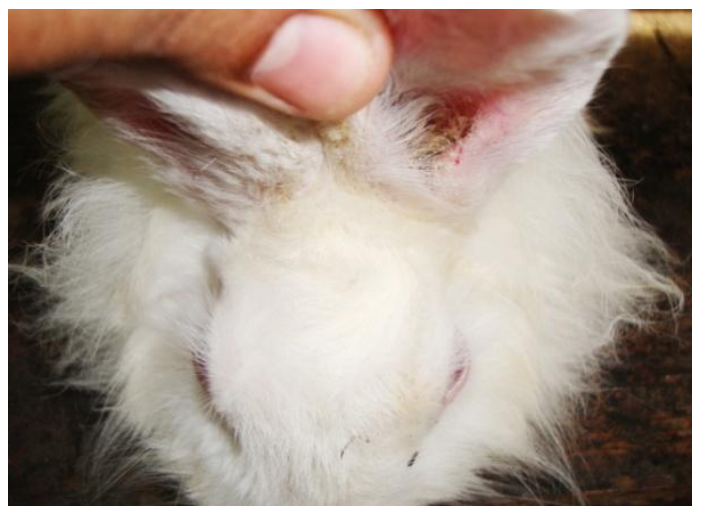

Fig. 1: Rabbit with ear cankar and ear marginal crusts.

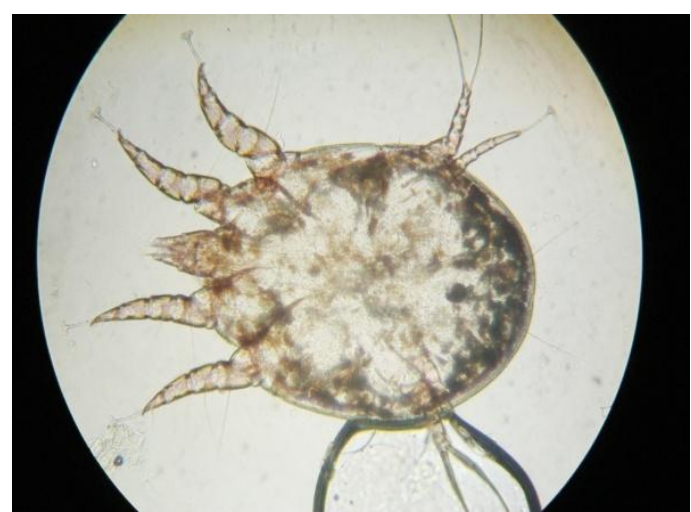

Fig. 2: Adult Psoroptes mites in skin scrapings $(40 \mathrm{x})$ 


\section{Conclusion}

In the present study rabbits infested by the Psoroptes cuniculi mange mites were successfully cured by using single dose of subcutaneous ivermectin along with ten doses of oral ivermectin @ $200 \mu \mathrm{g} / \mathrm{kg}$ body weight. Antibiotic therapy was initiated to control the secondary bacterial infections associated with ear canker.

\section{Acknowledgements}

First author thank full to Mr. S.Sadasiva Reddy (Reporter) for his help while collecting the clinical samples regularly.

\section{References}

[1] G.S. Aulakh, J. Singh, L.D. Singla, N. Singla, Pathology and therapy of natural notodric acariosis in rabbits. Journal of Veterinary Parasitology, 2003, 17: 127-129.

[2] R. Ravindran, V. Jayaprakasan, H. Subramanian, Circulating antibodies against Psoroptic mite antigens in hyperimmunised and infected rabbits, Journal of Veterinary Parasitology, 2000, 14: 55-57.

[3] A.K. Fajimi, A.A. Taiwo, E.A. Adebowale, F.I. Ogundola, Evaluation of sheabutter plus salt against naturally acquired psoroptic mange in rabbits. Tropical Veterinarian, 2002 20(1): 11-16.

[4] P.S. Jana, C. Guha, S.B. Saha, U. Biswas, S. Datta, S. Baksi S, Clinicopathological and therapeutic studies on natural Psoroptic acariosis in rabbits. Bangladesh Journal of Veterinary Medicine, 2004, 2(2): 155-158.

[5] Olaf Hansen, Yvonne Gall, Kurt Pfister, Wieland Beck, Efficacy of a Formulation Containing Imidacloprid and Moxidectin Against Naturally Acquired Ear Mite Infestations ( Psoroptes cuniculi ) in Rabbits. J Appl Res Vet Med. Vol. 3, No. 4, 2005. 281-286.

[6] E.J.L. Soulsby, Helminths, arthropods and protozoa of domesticated animals, $7^{\text {th }}$ Ed. Bailliere Tindall, London, 2006, 482-486.

[7] B.S. Reddy and K.N. Kumari, Demodicosis and its successful management in dogs. Indian journal of field veterinarians, 2010, 6(2), 48-50

[8] S.Sivajothi, B.Sudhakara Reddy, V.C.Rayulu, Management of Sarcoptic Mange in Rabbits, International Research Journal of Life Sciences. 1, (1), 2013, 21-25. 